\title{
RESSONÂNCIAS E ONTOLOGIAS OUTRAS: PENSANDO COM O PENSAR BANTU-KONGO
}

\author{
Tiganá Santana Neves Santos ${ }^{1}$
}

\begin{abstract}
Resumo: À luz de aspectos fundamentais do pensar bantu-kongo e em consonância com pensadores contemporâneos, tais como Bunseki Fu-Kiau e Zamenga B., este artigo aspira a refletir acerca de ontologias distintas daquelas hegemônicas euro-ocidentais. Tais ontologias são vivenciadas em parte do continente africano e foram deslocadas para territórios afrodiaspóricos, como o Brasil, ainda que com adaptaçóes, por meio de práticas cosmológicas que situam a ancestralidade em lugar central. As ideias de "mesmo pluriontológico" (conforme nós cunhamos, com base hermenêutica na filosofia kongo), opacidade (a partir da sugestão teórica de Édouard Glissant), estágios do cosmograma kongo, vazio, transmutação, inclinação à outridade, ciência do feitiço, sistema, entes ecológicos, inter-açóes propóem possibilidades complexas de ser-viver, em relação, as quais se distanciam, radicalmente, de metafísicas e éticas desenvolvidas no seio do pensamento ocidental, assim como podem com elas dialogar, o que faz com que, ao pensar do lado da margem afrodiaspórica do Atlântico, consideremos as tensōes entre esses distintos modos de pensar que ocupam espaços assimétricos nos construtos históricos.
\end{abstract}

Palavras-chave: Filosofia bantu-kongo. Ontologia. Mesmo pluriontológico. Outridade. Entes ecológicos.

\section{INTRODUÇÁOO}

De um certo Ocidente, a virada filosófica levinasiana, em que a ética precede à ontologia, pode oferecer caminhos de diálogo que despertam interesse, face ao que pretendemos destacar, nestas linhas textuais que se esboçam. Sobretudo, vetores da filosofia kongo africana, os quais nos chegam pelos pensadores congoleses Bunseki Fu-Kiau e Zamenga B., ao lado de

1 Professor Adjunto do Instituto de Humanidades, Artes e Ciências Prof. Milton Santos (IHAC) - Universidade Federal da Bahia (UFBA), Salvador, BA - Brasil. (D) https://orcid.org/0000-00032098-0715. E-mail: tigana.santana@ufba.br.

https://doi.org/10.1590/0101-3173.2022.v45esp.09.p149

\section{(i)}


outros pensadores, bem como se fazem presentes em urdiduras do que, nomeadamente, desde os anos de 1960, se chamou de diáspora negra, são o que colocamos em relevo, num modo de pensar a tornar fundíveis ontologia e ética ${ }^{2}$, considerando-se a centralidade da opacidade, da transmutação, da pluralidade/multiplicidade e de uma ciência do feitiço (kindokilmpandu) - ou ciência do conhecer. A nosso juízo, é relevante, aliás, tomarmos tais aspectos fundamentais da filosofia kongo - conforme, evidentemente, a interpretamos - enquanto outra experiência filosófica em complexidade.

Somos, ao que parece, diuturnamente convocados a denunciar a tendenciosa petrificação histórico-conjuntural da universalidade de cosmologias eurolinhageiras. Diante da cada vez mais delgada defesa de uma possibilidade de existência efetiva de universalidade, enquanto "natureza" emanada na/da cultura localizada na regulação dos eventos e cosmovisões, é preciso que se assevere que conceber qualquer "lei" ou perspectiva ontologicamente universal, dificilmente, não será prática etnocêntrica (para nos aproximarmos do esteio antropológico); ou seja, a ideologia propalada pelo eixo ocidental dominante, desde a sua projeção colonial, se continuada no espírito hodierno, confirma-se no seu locus de universalismo militante.

É claro que, à guisa de contextualização histórica das ideias no Ocidente, não nos reportamos às universalidades aventadas por Platáo e por Aristóteles, enquanto agentes conscientes e proponentes (da maneira como se desenha, a partir da Modernidade) da colonialidade de um pensar único. Mas a "necessidade", em sentido aristotélico, de uma origem grega da filosofia, bem como a herança, por "direito" e ressonância, dessa exclusividade por uma Europa-Ocidente germanocêntrica, conforme verificável em asserções de Heidegger (1997), por exemplo, situam-se numa construção etnicizada da filosofia, em grande conexão com a narrativa moderno-contemporânea da universalidade, com base em uma especificidade que não se reconhece como tal, a não ser qual excepcionalidade ou destinação enlevada.

Imaginamos que os potenciais leitores dessas palavras, as quais não trazem qualquer novidade às imagens do pensamento, já tenham, pelo

\footnotetext{
2 A proposta filosófica oferecida por Mogobe Ramose, na importante presença teórica do ubuntu, já integra e torna copertencentes ontologia, ética e epistemologia. O filósofo brasileiro Wanderson Flor do Nascimento, num artigo intitulado "Aproximaçôes brasileiras às filosofias africanas: caminhos desde uma ontologia ubuntu", de 2016, analisa e remete-se a aproximaçôes com a filosofia ubuntu na sua chave ontológica - não raro, tal complexidade originária dessa sistematizaçáo filosófica é encoberta por uma ênfase na sua potência ética ou para se pensar em termos de uma filosofia política (ainda que outra, em relação às vertentes estimuladas pelas esferas ocidentais).
} 
menos, emitido perguntas ao universal, sem que tal invenção funcional tenha sido responsiva ou conclusiva, de modo a cobrir todos os buracos das paisagens das existências. Iniciamos a nossa exposição com essa brevíssima crítica porque, no limite, este texto trata de um panegírico ao contrauniversal e, mais que isso, ao singular - como um multíplice comum que se cultiva com acentuação existencial própria. Sem essa sustentação propedêutica, não poderíamos ter com uma chave de pensamento que, ao menos, desestabiliza a nada desconhecida narrativa hegeliana da unívoca possibilidade de pensar, isto é, em última análise, do humano possível somente se advindo do meridiano europeu de racionalidade. Não aspiramos a uma aproximação com a virtualidade do total, a não ser aquele assumidamente parcial e específico. B (1996, p. 11) - pensador contemporâneo, como Fu-Kiau (1978, 2001a, 2001b, grifos do autor) - traz-nos uma ideia-experiência de totalidade kongo, enquanto conjunto de interaçôes: "O mundo está intimamente ligado e forma um TODO. Não há nem vazio nem espaço. Há sempre, entre dois elementos diametralmente opostos, totalmente diferentes por sua aparência, um ponto ou pontos de injunção por meio dos quais se operam as interaçóes." ${ }^{3}$

Eis, numa primeira leitura, a formulação de uma ética que chamaríamos de ecológica - com aproximações e distanciamentos em relação aos pensamentos de Jonas (2006) e Unger $(1991)^{4}$, por exemplo. Nessa ética ecológica, acrescente-se a não possibilidade real de que se estabeleça uma ordenação quanto a precedências e subsequências cronológicas ou espaço-temporais, no que concerne à interaçáo entre o insondável e o que se apreende diretamente; não é desejável, aliás, abarcar a referida interação dentro dos binômios causa-consequência e anterioridade-posteridade, içados pela linearidade. Regressaremos a essa análise mais adiante.

\footnotetext{
${ }^{3}$ Tradução nossa para o trecho original em francês: Le monde est intimement lié et forme un TOUT. Il n'y a ni vide ni espace. Il y a toujours entre deux éléments diamétralement opposés, totalement différents par leur apparence, un point ou des points d'injonction à travers lesqueles, s'opèrent les interactions.

${ }^{4} \mathrm{~A}$ vizinhança teórica entre o que estamos a desenvolver, neste texto, e os autores elencados, a saber, Hans Jonas e Nancy Mangabeira Unger, se revela, no que tange ao reconhecimento da fundamental importância de preservação das diversas forças presentes no que se chama de natureza, da qual o ser humano é inerentemente partícipe, pelo fato de se viver e pensar a partir do que vive. Os distanciamentos teóricos dâo-se por pensarmos com base em outra chave ontológica e outra cosmologia propriamente, $\mathrm{o}$ que faz com que os citemos, apenas por ora, em todo o artigo, a título de exemplificação de pensadores aos quais é cara a ideia de ecologia, sob o ponto de vista filosófico.
} 


\title{
1 Kolo Diakanga Nganga, Kutula Nganga - Kolo feito só É Desfeito por QUEM SABE O QUE É Kolo
}

A sentença proverbial (kingana) que introduz esta seção, originalmente, enunciada em língua kikongo, diz respeito a um aspecto basilar numa das camadas da ética kongo: não se adentra um sistema cosmológico sem o conhecer, isto é, sem que ele se abra à alteridade. O conhecimento (nzayilu) dá-se diante da dinâmica do que Fu-Kiau (1978) chamou de "comunicação sensorial" (ndotolo), evento constitutivo dos entes e da esfera do impalpável, marcado pelas ondas e radiaçóes (minika ye minienie), em constante comutação, as

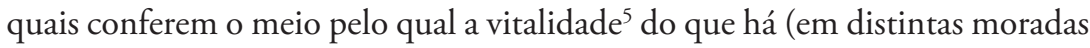
de temporalidade) se realiza e presentifica. Kolo é, entre outras acepçóes, código ou nó. Há que se decodificar um sistema (kimpalfu), para se lidar com ele. Entenda-se sistema como qualquer vetor ôntico ${ }^{6}$ autônomo a atuar, necessariamente, de forma, além de intra, intersistêmica. Tal perspectiva emitese a partir da experiência humana (enquanto perspectiva ${ }^{7}$ ), o que náo implica

\begin{abstract}
5 O missionário belga Placide Tempels, no fim da primeira metade do século XX, a despeito de ter levado a sua percepção estrangeira (e, em larga medida, eurorreferente) à cosmologia, sobretudo, dos baluba, na atual República Democrática do Congo, foi o primeiro a reconhecer, diante das hegemonias com as quais ele próprio partilhava elementos culturais de origem, a existência de uma filosofia na África subsaariana, com a publicação da obra $A$ filosofia bantu (em tradução para a língua portuguesa). Originalmente escrita em holandês e traduzida para o francês, em 1945, nela, o autor traz-nos o conceito luba (estendido a outras civilizaçôes bantu) de "força vital", enquanto proposta de outra ontologia. A "força vital", na sua dinâmica de intensidade, ocuparia o lugar ocidental do "ser". Aqui utilizamos a ideia de vitalidade com uma subentendida dimensão de força. No entanto, com olhar atual, discordamos da asserção generalista que nos fala de uma "filosofia bantu". Pensemos na diversidade filosófica a circunscrever as cerca de seis centenas de civilizaçóes que se inserem nessa estrangeira classificação, a rigor, linguística, sistematizada, já na segunda metade do século XIX, pelo linguista alemão Wilhelm Bleek. Não estamos de acordo, também, com a concepção binária de que a relação humana com a "força vital" se bifurca entre o aumento ou redução desta, com as implicaçôes cabíveis a tal gradação. A vitalidade à qual aludimos, fundada nas referências kongo, é, em si mesma, a experiência por meio da qual o mundo-natureza se dá à pessoa kongo e pela qual ela (a pessoa) se faz partícipe fundamental, quer da face, de algum modo, tangível à compreensão, quer dos elementos desconhecidos desse mundo.
\end{abstract}

${ }^{6}$ Ao retomarmos o termo "ôntico", trazemos à baila a conceituação heideggeriana quanto à existência concreta do Dasein - usualmente, traduzido em português como Ser-aí -, ou, em termos mais gerais, trata-se de uma adjetivaçáo filosófica relativa ao ente.

7 Perspectiva, aqui, não evoca o conceito de "afroperspectividade" desenvolvido, no Brasil, principalmente, pelo filósofo Renato Nogueira, nem o "perspectivismo ameríndio" creditado ao antropólogo brasileiro Eduardo Viveiros de Castro. A palavra, nesse caso, associa-se, de forma direta, a uma ideia corrente de "percepçáo". Contudo, não nos reportamos propriamente à "cosmopercepçáo" trazida à baila, com relevo, pela pensadora nigeriana Oyeronke Oyěwùmí, numa complexa e importante crítica à centralidade dada à visão/visualidade pela esfera colonial, pelo que propốe uma cosmopercepção iorubana, por exemplo, em lugar de cosmovisão. A esse respeito, no que toca à cosmologia kongo, há uma pluralidade de centralidades nas percepçôes que inclui a visão; assim como, 
que as autonomias dos entes se originem ou solicitem anuência para existir, no mundo-natureza, ao humano (muntu), ou seja, que estejamos a dialogar com um pensar antropocêntrico (ou mesmo tão somente antropomórfico) em dimensōes ontológicas.

Há o reconhecimento radical de que o mundo, conclusivamente, não é uma invenção humana, ao tempo em que é, também, uma experiência inventada pela mirada humana - e, claro, pela mirada humana kongo, pontualmente; muntu é pessoa como um(a) mukongo vivencia e teoriza (ainda que não exclusivamente). Nesse sentido, o estabelecimento das relaçóes tem seu ponto nodal (e vibrátil), em função do aludido muntu, de acordo com FuKiau (2001a, p. 114, grifo nosso.): “[...] uma pessoa [...] representa o kolo (nó) mais vibrátil das relaçóes." ${ }^{8} \mathrm{O}$ sistema com o qual se lida, kimpa, é, também, mistério (kimpa), donde haverá sempre algo que não se dá a conhecer em tudo o que se dinamiza na vitalidade manifesta. $\mathrm{O}$ que se re-vela, na medida em que (se) apresenta, vela(-se) de novo.

O mundo-natureza (bem como os dois termos, separadamente) solicita-nos o sentido de tudo o que ocorre como evento ou força, conforme nos indica Fu-Kiau (manuscrito, 1978), ao se referir à acepção notadamente pré-colonial da palavra nzambi:

[...] o termo kongo "nzambi", para além do seu novo sentido religioso ocidental de "deus" cristão, significa, originalmente, "natureza, natural, fundamental, terra, força, catástrofe, morte" etc. Pode-se verificar tal sentido em muitas expressóes ainda correntes nos nossos ambientes kongo:

Ludi evo kedika kia nzambi - É a verdade natural

Nzambi utubeki - A morte nos atingiu

Nzambi yokele - Uma força invisível nos silenciou

Lufwa lwa nzambi - Uma morte natural

Kandu bia nzambi - Tabus naturais

Mangu bia nzambi - Mistérios naturais. ${ }^{9}$

não raramente, se verifica uma espécie de sinestesia na ocorrência perceptiva, conforme ratificado no aforismo, enunciado por Fu-Kiau (2001a), que afirma: Wa i mona ye mona i sunsumuka - Ouvir é ver e ver é sentir/reagir.

${ }^{8}$ Todos os excertos desse filósofo-autor citados no texto foram traduzidos por nós. Nesse caso, a obra original fora escrita em inglês: a person [...] represents the most vibrating kolo (knot) of relationships.

${ }_{9}^{9}$ Originalmente, em seu manuscrito aqui citado, Bunseki Fu-Kiau, em francês e kikongo, assim escreveu: [...] le terme kongo "nzambi", à part son nouveau sens religieux occidental de "dieu" chrétien, signifie à l'origine "nature, naturel, fondamental, terre, force, catastrophe, mort", etc. Ce sens peut se vérifier dans beaucoup d'expressions toujours courantes dans nos milieux kongo: 
Bunseki Fu-Kiau, em sua obra, mais panoramicamente, reportase a nzambi, entre outras alcunhas-conceito, como nkingu-nzambi, ou seja, princípio-nzambi, além de princípio-natureza e princípio-mudança. Por seu turno, o pesquisador angolano Batsîkama (2019) traz-nos uma compreensão de nzambi associada a deus, ainda que como, igualmente, "Espírito da Existência", em se manifestando no elemento terra. A manifestação do referido "Espírito da Existência", o qual também chamou de "Espírito de Deus", seria nomeada, distintamente, para os bantu-kongo, de acordo com o elemento fundamental da natureza por meio do qual ocorresse, a saber: kalûnga - água(s); mbumba - ar; nsuku/nsûndi - sol/luz. Ainda conforme Batsîkama (2019, p. 481), nesse caso, em diálogo com Albert Doutreloux, tem-se $\mathrm{e}^{10}$ : "Derivado do verbo yâmba (ou zâmba), o substantivo Nzâmbi implica a ideia de fixação e de edificação primitiva: a criação da terra por um Espírito maior que esta última."

Notemos que, mesmo a partir de uma associação com uma acepção mais cristã de expressão superior divina, o jaez de força ou espírito (se se quiser) natural parece manter-se, substancialmente, em nzambi. E é, precisamente, o complexo sistema-mistério ( $k i m p a)$ evocado e vivenciado enquanto natureza que torna sempre presente tudo o que seja fundamental experienciar, conhecer, sentir, pensar e reverenciar - esta última ação não implica uma categorização religiosa, principalmente, se considerarmos uma configuração sócio-histórica não colonial; a reverência a que aludimos, diferentemente, incorpora um adensado respeito ao que vive e ao que viveu.

\section{MUNDO-NATUREZA É FUTU DIA N'KISI DIAKANGA KALUNGA MU DIAMBU DIA MOYO, ISTO É, UM EMBRULHO DE MEDICAMENTOS ATADO POR KALUNGA PARA QUE HAJA VIDA}

$\mathrm{O}$ aforismo kongo acima, trazido à baila ao mundo ocidental por FuKiau (2001b), sem a distinção quanto a nomes-marco do que apresentou

Ludi evo kedika kia nzambi - C'est la vérité naturelle

Nzambi utubeki - La mort nous a frappés

Nzambi yokele - Une force invisible nous a fait taire

Lufwa lwa nzambi - Une mort naturelle

Kandu bia nzambi - Tabous naturels

Mangu bia nzambi - Mystères naturels.

${ }^{10}$ Patrício Batsîkama dialoga teoricamente, nesse excerto, com as pesquisas de Albert Doutreloux; especificamente, com a sua obra L'ombre des fétiches: société et culture yombe, de 1967. 
Batsîkama (2019), como "Espírito de Deus", conforme vimos anteriormente, posiciona kalunga na mesma potência e realização de vitalidade que nzambi. São o mesmo acontecimento na pluralidade do que existiu, existe e habita os devires na malha das possibilidades. Embora tenhamos versado acerca de kalunga, em trabalhos anteriores (SANTOS, 2019a; SANTOS 2019b), reencarnamos algumas das suas diversas leituras ontológicas, em bantucosmologias, a fim de seguirmos com a devida importância das vivências pertencentes ao mundo-natureza, no nosso trajeto.

Kalunga (ou nzambi), lugar de "justeza" e "razão"11 - prestemos atenção ao fato de kuma, "lugar", ser também razão, em kikongo - , é a ação de transbordar o vazio (kalunga walunga mbungi) (FU-KIAU, 2001a), para que as engrenagens de manifestaçóes múltiplas de vitalidade se deem. Além disso, trata-se de vida com base em si. Kalunga dá a conhecer e a desconhecer, simultaneamente, já que mantém nós atados em meio ao que se desnuda como vida e vida "evidente". O que nos poderia, entre outras coisas, propor uma ontologia que traz a vida, enquanto transbordamento do vazio? $\mathrm{O}$ que poderia ser o vazio? O que poderia ser transbordamento?

Transbordar ou ultrapassar as bordas designa um deslocamento, uma trans-dução (tradução) que percebemos como sendo, nesse caso, de ambitude ontológica. É verdade que se pode interpretar essa ontologia, como força relacional, entre vazio (mbungilwulu) e kalunga, o que nos traz um complexo originário, no que tange ao que vive; no que tange, portanto, ao que chamamos aqui, sinteticamente, de ecológico - num senso a sublinhar o que vive e suas mais diversas interaçóes. O "ir além das bordas", transir, é o estabelecimento (movente) de um lugar. Razão é lugar, como vimos, enquanto potência e realização de acontecimentos. Aqui, razão não é racionalismo nem se fecha em categoria de entendimento e certa apreensão do real ou de fenômenos; nem mesmo é um atributo de diferenciação humana de propriedade do modo humano de vida. O humano (mu-ntu por ou em $n t u$ ) move-se existencialmente por $n t u$ - traduzido, usualmente, como cabeça, lugar de ngindu, pensamento em disposição expandida a incluir sentimento, movimento, razão, sonho etc. - , mas ntu desvela-se e transmuta-se noutros entes.

Nesse sentido, ntu é uma potência polimorfa nos corpos ecológicos, a qual se presentificará com diferenças, muitas vezes, significativas. Um

\footnotetext{
${ }^{11}$ Segundo o Novo Dicionário Português-Kikongo, de COBE (2010), a expressão "ter razão" é lunga. Por seu turno, "dar razão" é lungisa, assim como na língua-irmã do kikongo, o kimbundu.
} 
importante limite posto pela opacidade própria do sistema de vivências, para lembrarmos o pensamento relacional de Édouard Glissant, não permite que, efetivamente, conheçamos o "lugar" (kuma), ou "razão" (kuma), em que se dão os deslocamentos ontológicos. Consoante começamos a discutir, neste artigo, sistema (kimpa) é mistério (kimpa), principalmente, do ponto de vista da sua operação imanente. Transbordar é transmutar-se, e situar-se entre o desvelamento e a opacidade (própria do que se manifesta e acontece).

$\mathrm{O}$ oco $(w u l u)$ trespassado por kalunga distingue-se do nada (aqui trazido como não-ser, sobretudo), no que concerne, por exemplo, ao "imperscrutável”, de acordo com o grego Parmênides de Eleia. A ontologia é de outra sorte, nessa paisagem que estamos a intuir - em sentido latino - , de modo a não estarmos, em verdade, a pensar sobre a conhecida dualizaçáo ser/não-ser. O nada heideggeriano, se bem que faça parte do ser do que existe, diferencia-se do oco introduzido por kalunga. E mesmo o que se "nadifica", numa acepção sartriana, não seria uma referência, em perspectiva ocidental, para o estabelecimento de uma conexáo com a presença do insondável que participa da vida corrente bantu-kongo. Apresentamos, em outras ocasióes, entre escritos e conferências (especialmente em SANTOS, 2019a), discussões em torno dos estágios ontológicos que se entrecruzam em haste vertical e haste horizontal do cosmograma kongo (dikenga dia kongo), configurando a complexa imagem-conceito de uma cruz (yowa), cujas extremidades demarcam o náo visto (musoni), o que desponta (kala), o que chega ao cume de uma realização (tukula) e o que se desintegra de uma fisicidade visível (luvemba).

Concentremo-nos, ora, num dos estágios - a despeito de os entes e situaçóes, segundo o que a filosofia kongo poderia sugerir, não se deixarem atravessar por cada estágio de maneira estanque e sequencial, mas pela relação desses estágios. Musoni (estágio do que náo se dá a conhecer ou ver) é uma palavra, em kikongo, advinda do radical verbal sona, o qual significa registrar, gravar, insculpir, como também, segundo MacGaffey (1986, p. 51), “[...] fazer marcaçôes rituais no corpo" ${ }^{12}$, já que nsona e nkandu eram dias da semana kongo dirigidos aos ancestrais (bakulu) e próprios para se "[...] emergir de isolamento ritual"13. Musoni compóe-se, provavelmente, do que Fu-Kiau (2001a) chamou de ndobe ou piu - matéria escura - , a partir de que os acontecimentos se expandem em forma de $\mathrm{V}$, tendo no vértice dessa outra imagem-conceito o que submerge no escuro originário. Mu-soni é estar por dentro (prefixo $m u$ ) do

\footnotetext{
${ }^{12}$ Originalmente: to make ritual markings on the body.

${ }^{13}$ emerging from ritual seclusion.
} 
escuro que ilumina - lembremo-nos de que tal estágio pensado como o "sob a terra" ou como o "sob as águas" inscreve-se pela rutilante cor amarela para os ba-kongo. A matéria escura é "localização" possível de registros potenciais do que pode vir a ser manifestação:

É a forma mais primitiva que emergiu do fundo da primeira matéria, "a matéria escura" [ndobe/piu], que é a "sala de impressão" de todas as realidades, não apenas visíveis e invisíveis, mas materiais e imateriais. Uma "sala de impressão" para realidades que foram e realidades por vir. A "sala de impressão", dentro da qual todas as grandes ideias, imagens e formas emergem para serem fecundadas em nossas mentes. Subsequentemente, nós as criamos como realidades. (FU-KIAU, 2001a, p. 141). ${ }^{14}$

É importante salientar que o oco originário (wulu atuka), ao mesmo tempo, não remete a um início nem a uma cosmogonia com sequências, ou seja, a uma gênese cronológica, mas a uma percepção geradora. Os estados prenhe e parturiente de realidades são ubíquos, já que musoni está nos existentes, de modo semelhante e distinto aos demais estágios ontológicos. Musoni é uma potência "mistério-manifestação" que diz respeito ao que vive, e ao que se extingue - quando na via contrária - a se deslocar do emerso ao imerso. Bunseki Fu-Kiau, de acordo com a citação em destaque acima, diznos, também, das realidades que criamos, haja vista serem as pessoas sistemas de sistemas, em consonância com a cosmologia kongo. Como tais, concebem outros sistemas.

A vida-kalunga, ao transbordar o vazio, leva-nos a uma hermenêutica do que chamaremos, doravante, de "mesmo pluriontológico". O que trazemos como "mesmo", não numa abordagem levinasiana nem heideggeriana, tampouco evoca uma identicidade, em solilóquio, a qual se volta a si, em âmbito equacional e autorreferente. "Mesmo" é a generalização que se assume sem ferramentas de absorção inteligível de um acontecimento, entregando-se à complexidade de saída e àquela de chegada a que não se chega. $\mathrm{Na}$ medida em que seja um sistema ou força autônoma vista de fora $(f u)^{15}$, o opaco é o "mesmo"

\footnotetext{
${ }^{14}$ Originalmente: It is the most primitive form that emerged from the depth of the first matter, "the dark matter" (ndobelpiu), which is the "printing room" of all realities, not only visible and invisible, but material and immaterial as well. A "printing room" for realities that were and realities to come. It is the printing room inside where all great ideas, images and forms emerge to be impregnated in our minds. Thereafter, we create them as realities.

15 Segundo o poeta e semioticista angolano Abreu Paxe, um mukongo com quem conversamos exaustivamente, haveria, numa das variantes do kikongo, uma sutil diferença terminológica entre o sistema experimentado por dentro (kimpa) e o sistema observado de fora $(f u)$.
} 
- equivalente a si, enquanto opacidade, por uma intuição ou aproximação, ao que se sabe, externa por parte de quem o faceia sem apreendê-lo - que, a rigor, não estaria numa topografia.

O incapturável é pensado e vivido no centro da comunidade kongo; ele não é frequentado por uma certa forma de conhecer a que vínhamos nos referindo até então. É possível conhecê-lo, "outramente", como participação intangível, presença inefável, corpo-ausência, sobretudo, dada a sua importância. Conhece-se o que é importante. "Mbungi a kanda va kati kwa nsi ye yulu - $\mathrm{O}$ vão originário da comunidade, no centro, entre a terra e o céu”, diz uma sentença em linguagem proverbial que traduzimos da obra de FuKiau (2001a). Essa insondabilidade do ausente-presente, numa interpretação das poéticas de musoni, gera sondáveis presentes que vivem - não como início de mecanismos, mas como fonte - , em geral, de forma múltipla, e, assim, multiplamente, é também o que gera. Desse modo, dá-se o outro conhecer do escuro-origem: como percepçáo do que não se distingue, em estado de mistério, e como presença genética no que floresce à vida e à morte (no âmbito de memória motriz, isto é, tal como vida na memória do que vive).

\section{Desdobramentos do “MESMo PLURIONTOLÓGICo” E ATUAÇÁo DE KINDOKI}

São muitos "mesmos pluriontológicos", já que são multipresentes e infindáveis as forças centrífugas de gestaçấo de viventes. "Mesmos pluriontológicos" são "mesmos pluriviventes". Em tempo, cabe-nos positivar - por ora, assaz incompleta e sucintamente - que "viver", no âmbito da nossa reflexão, difere do onipresente "ser" da história do pensamento ocidental. Viver (zinga), sempre verbal, é também, em kikongo, o verbo kala - ser ou morar. Em alguma medida, o que vive se faz morada e apresenta o que é. No entanto, não parece fazer muito sentido uma identificação ontológica (no estrito senso metafísico ocidental de ser) precedente a uma experiência ecológica, ou seja, precedente a se viver em relação.

Nesse caso, o "rosto do Outro", conforme proposto pela obra filosófica de Emmanuel Lévinas, é devir (incluindo-se dimensóes de temporalidade e o imprevisível), experiência horizontal no mundo-natureza (lukongolo) e o diverso que compóe o si-mesmo morfológico, necessariamente, constituído por forças de externalidade em conexão com a corporalidade de partida. O corpo (nitulto), bem como seu movimento e transmutação, indicam o que viver traz à presença. A tangibilidade dos corpos é a concreção de viver. 
Viventes, portanto, são todos os corpos que constituem o ecológico. Não há, entretanto, a clássica separação científico-biológica entre o biótico e o abiótico. Em última análise, vive tudo aquilo que se relaciona, direta ou indiretamente, com o que vive. Os corpos, por sua vez, dispóem de distintas camadas de fisicidade. Ventos, frequências, sonhos e ancestrais, por exemplo, apresentam-nos disposiçóes corpóreas distintas daquelas das pedras, rios, tambores e árvores. Ter corpo é presentificar a ação de viver sob determinada maneira. A morfologia, desse modo, é uma forma de apresentar o que vive e, portanto, existe.

O que chamamos de "mesmo pluriontológico", não sendo início cronológico, mas, em lugar, força originária a qualquer tempo, é o próprio viver quando acontece. Kalunga transbordou o vazio, porque o vazio é também kalunga. Assim, vazio-kalunga transbordou kalunga-vazio. Não haveria um elemento unitário que seria a ignição do processo vital. Pensa-se numa relação originária, a qual não começa com elementos postos um a um linearmente. Kalunga e vazio acontecem. Náo se pensa fora desse acontecer constante, assim como, na física, a cosmologia convencional, a qual se organiza, fortemente, com teorias desde o século $\mathrm{XX}$, em linhas gerais, não pensa nem o tempo nem leis da física fora da propulsão do big bang.

O vir-a-viver marcado pela transmutação do vão originário em (viv)ente - o que solicita, concomitantemente, mutação e preservação do "mesmo pluriontológico" - orienta-nos quanto a conceber um pensamento filosófico alicerçado em base mosaicizada constituída por mistério evidente, movimento ontológico, variação, imprevisibilidade e relação. Viver, por sua vez, permanece com o que vive, compondo o chão da prática civilizatória kongo. A experiência ecológica, a qual depende de vazios ocupantes, é uma experiência de tradução, se a compreendemos qual trânsito de variação, num direcionamento de trans-dução. A opacidade do "mesmo pluriontológico" desdobra-se num (viv)ente que pode variar-se noutras ontologias, intersemioticamente, por carregar o kundu para ser outro - e essa "outridade" não apaga, necessariamente, a "mesmidade". Assim, também, podem ser vividas temporalidades distintas no mesmo (enquanto um complexo de mutações e permanências) corpo, a saber, átimo-devir e transversalidade temporal de quem e do que veio antes, legando a própria memória material e/ou imaterial do corpo sobre o qual incide a fachada de tudo o que (lhe) ocorre. Sobre o kundu, escrevera B. (1996, p. 15-16): 
Um pai que gostaria de ver seu filho acessar kinganga ou um saber transmitelhe a totalidade ou uma parte do seu KUNDU ${ }^{16}$, de suas aptidóes.

Na concepção africana, particularmente, entre os KONGO, um KUNDU seria um dos numerosos átomos ou baterias que constituem o corpo humano $[\ldots]$

Não existe somente KUNDU para adquirir conhecimento; certos kundu são relacionados a animais e até plantas. Dir-se-á de alguém que possui um crocodilo, uma jiboia, uma víbora etc...

Mas, na verdade, em termos científicos, KUNDU não é senão uma aptidão, um dom inato ou adquirido [...]. ${ }^{17}$

Fu-Kiau (2001a, p. 37-38) acrescenta que kundu é, na verdade, kindoki. $\mathrm{O}$ conhecimento, o feitiço, a ciência, as aptidóes, por si, assim como se manifesta a natureza, não são, precipuamente, positivos ou negativos. Ademais, trata-se de uma aptidão e conhecimento que não se restringem:

No mundo espiritual, kundu, kindoki é o elemento mais importante e central de tal lugar insondável. Esse elemento é constituído pela experiência baseada em bibulu (b), incluindo-se o ser humano, em simbi (s), isto é, experiência ancestral, e em mpeve $(\mathrm{m})$, a saber, experiência alma-mente. Nesse caso, kundu ou kindoki é o conhecimento vivido e acumulado [...] Kindoki, igualmente nzailu, é um entre os termos equivalentes à ciência na língua kikongo, e, como em todo conhecimento, possui o seu lado positivo e também o seu lado negativo. Kindoki, Nzailu e Bumpitu são termos sinônimos, contudo o último é mais apropriado para química do que para ciência. ${ }^{18}$

\footnotetext{
${ }^{16}$ Todos os grifos são do autor.

${ }^{17}$ Trecho original: Un père qui voudrait voir son fils accéder au kinganga ou un savoir, lui transmet la totalité ou une partie de son KUNDU, de ses aptitudes. Dans la conception africaine, particulièrement chez les $K O N G O$, un KUNDU serait l'une de nombreuses atômes ou batteries qui constituent le corps humain [...] Il n'y a pas seulement de KUNDU pour acquérir des connaissances, certains kundu sont en relation avec les animaux et même les plantes. On dira de quelq'un qu'il a un crocodile, un boa, une vipère etc. Mais en fait, en termes scientifiques, KUNDU n'est autre qu'une aptitude, un don, inné ou acquis [...]

${ }^{18}$ Originalmente: In the spiritual world the kundu, kindoki, is the central and most important element in this unfathomable world. This element is made up by the experience based on bibulu (b) including human being, the simbi $(s)$, i.e., ancestral experience, and on mpève $(m)$, i.e., soul-mind experience. In this case kundu or kindoki is the lived and accumulated knowledge [...] Kindoki, nzailu likewise, is one among the equivalent terms of science in kikôngo language, and as to every knowledge it has its positive side as well as its negative one. Kindoki, Nzailu and Bumpitu are synonymus terms, but the last is more proper in lieu of chemistry than in lieu of science.
} 
Para além do mundo humano, há uma ciência a operar na natureza que pode fazer com que um ente (também) seja outro, diferencie-se, rearrumese. No mundo humano (parte do mundo-natureza), assegura-se que, ao lado da predisposição a mutaçóes que acontecem à revelia da sua consciência ou vontade, pode haver o aprendizado de kindoki, ciência cujo cerne está na assunção de viver como transmutação efetiva e como interação. Voltemos às palavras de B. (1996, p. 11): "KINDOKI ${ }^{19}$ não é outra coisa senáo o conjunto das INTERAÇÓES, esses elos que nos unem ou nos diferenciam e sobre os quais pode-se agir se se quer ter uma mudança num sentido ou noutro [...]." ${ }^{20}$ Usualmente, traduzido para línguas ocidentais modernas como "feitiço", de fato, kindoki diz respeito a um "feito".

Contudo, não tem qualquer associação verdadeira com o significado pejorativo infligido pelo olhar colonial. A ciência ou feitiço é eficácia (em certa aproximação antropológica, sem se circunscrever pela "eficácia simbólica"), além de fundir prática e reflexão; é epistemologia diante do caráter movediço do que se relaciona com compor as ocorrências no/do mundo. O ndoki, ou seja, o conhecedor praticante de kindoki, como um xamá em alguma parte da floresta amazônica, habita os entre-lugares que podem pender a um estado-forma ou outro (ou outros), sem moralizar o conhecimento nem o próprio caráter transformativo que conduz toda uma ontologia e toda uma maneira de morar na terra. $\mathrm{O}$ feiticeiro, o cientista, o tradutor concentram-se na efetividade da transmutação e voltam-se a escutar o mistério do escuro, a fim de desembainharem outras cores concretas de realidades. Ressalta o pesquisador congolês Bockie (1993, p. 82):

Kindoki foi visto por pessoas de fora - e por muitos africanos ocidentalizados - enquanto sobrevivência de uma superstição "primitiva" que atrapalha o progresso e o desenvolvimento da sociedade Manianga. ${ }^{21}$ Mas, depois de me engajar nesse estudo, passei a considerá-lo um sistema complexo de pesos e contrapesos sociais que trabalha em prol da saúde e integridade, da preservação e continuidade da comunidade, capaz de oferecer oportunidades de riqueza, poder, conhecimento e dedicação ao bem comum, ao tempo em que controla os fatores disruptivos da raiva,

\footnotetext{
${ }^{19}$ Todos os grifos são do autor.

${ }^{20}$ Originalmente: KINDOKI n'est autre que l'ensemble des INTERACTIONS, ces liens qui nous unissent ou nous différencient et sur lesquelles, on peut agir si on veut obtenir une modification dans un sens ou dans un autre $[\ldots]$

${ }^{21}$ Trata-se da regiāo natal, na atual República Democrática do Congo, de Simon Bockie e de Bunseki Fu-Kiau.
} 
da vingança e da violência. Visto sob essa luz, o kindoki é uma ciência cultural sutil que serve a uma função vital. É uma conquista social impressionante que não pode ser facilmente abandonada. Suas raízes são tão profundas, que é provável que sobrevivam de formas adaptadas no curso do desenvolvimento social. ${ }^{22}$

$\mathrm{Na}$ afrodiáspora, como ressignificação do fundamental kundu dos bantu-kongo (tanto quanto kindoki), em territórios de espiritualidade, ritos e práticas filosóficas dos candomblés - para retomarmos a análise de Nascimento (2016b) - de matriz congo-angola, os reverenciados ancestrais da terra tornaram-se outros, já que a terra se tornou outra. Não é incomum, desde a formação dos calundus ${ }^{23}$, principalmente os de tronco bantu - estes são formas antigas de culto afro-brasileiro, anteriores aos candomblés como difundidos desde o século XVIII - , a presença de ancestrais e encantados, aos quais são atribuídas origens indígenas. Os caboclos (encantados ou ancestrais a que é muito frequentemente imputada uma "identidade" indígena), cultuados nas cosmologias dos candomblés, parte importante da heterogênea cosmovisão afro-brasileira, são os ancestrais-outros dos descendentes bantu.

A associação, fusão, paralelismo, adaptação ou estabelecimento de equivalências que muitos teóricos, desde Nina Rodrigues, posicionaram em torno do que se espraiou como "sincretismo religioso", no Brasil-considerandose as sólidas críticas mais contemporâneas a respeito dessa sinuosa conceituação (incluindo-se o "sincretismo de máscara", trazido por Roger Bastide, a análise "barroco-especular melancólica", de Emmanuelle Tall, ou a proposta de "repensar o sincretismo", de Sérgio Ferretti) ${ }^{24}$-, ao mesmo tempo em que podem introduzir um comportamento político, como reivindicam alguns pesquisadores, no assimétrico engaste entre colonizadores e subalternizados, apresentam a sua filosofia pluriontológica na qual uma coisa pode ser o que

${ }^{22} \mathrm{O}$ trecho que traduzimos no corpo do texto, originalmente, foi assim escrito: Kindoki has been viewed by outsiders - and by many Westernized Africans - as the survival of a "primitive" superstition that stands in the way of progress and the development of Manianga society. But after becoming engaged in this study, I have come to regard it as a complex system of social checks and balances that works for the health and wholeness, the preservation and continuance, of the community, capable of providing opportunities for wealth, power, knowledge, and dedication to the common good while controlling the disruptive factors of anger, vengeance, and violence. Seen in this light, kindoki is a subtle cultural science that serves a vital function. It is an impressive social achievement that cannot be easily abandoned. So deep are its roots, it is likely to survive in adapted forms in the course of social development.

${ }^{23}$ Ver estudos de alguns pesquisadores, como Mott (1994), Mello e Souza (2002) e Silveira (2009).

${ }^{24}$ Rodrigues (2006), Bastide (1967, 1995), Tall (2012) e Ferretti (2013) são, devidamente, situados na bibliografia deste artigo. 
se conhecia dela e coisa outra que se conheceu depois, simultaneamente. É preciso que entendamos "coisa" como entidade conjuntiva.

Entre essas entidades antes distantes, pois, vige a opacidade que as relaciona. Isso pode fazer com que forças da natureza, na cultura kongo, como simbiln'kisi, sejam si próprias (num "si" culturalmente nutrido por uma antiga coletividade) e, ao mesmo tempo, outras forças nas cosmologias iorubana e fon, a saber, orixás e voduns, conforme se pode verificar nas práticas sociais e ritualísticas dos candomblés, em todo o território brasileiro - algo análogo, guardadas as evidentes diferenças histórico-culturais, é corrente no seio da espiritualidade afro-cubana. A respeito dos mestres-outros - originalmente de fora das raízes kongo - , dentro dos quais se inserem os ancestrais-outros (que não, por isso, são outros ancestrais), Fu-Kiau (1978) identifica a sua presença e cultivo potenciais, entre os ba-kongo, por meio, principalmente, da sua prática filosófica. O reconhecimento social da mestria (kin’longi/kinganga) diz respeito tanto aos que vivem, biologicamente, quanto aos que vivem na memória da comunidade, afirmando-se, nesse caso, como ancestrais (bakulu):

O pensamento filosófico kongo não é tribal nem racial [...] É uma filosofia que reverencia o bom mestre, mesmo que ele tenha emergido fora do círculo kongo; trata-se da aplicação sistemática do princípio políticofilosófico de "konso kwela mama (nkumbu andi), tata" - quem quer que se case com nossa mãe é nosso pai - , se ele pode afirmar, por suas qualidades, que é um "pai" (chefe) para a nossa sociedade kongo. ${ }^{25}$

Nos mesmos manuscritos, numa passagem, mais adiante, Fu-Kiau (1978), trata particularmente dos mestres mortos e do acesso ao seu vulto, por parte da comunidade kongo: "[...] as radiaçóes das ondas dos grandes mestres, bakulu bakula, de todas as épocas e de todas as civilizaçóes que lhe atingem a mente através dos sonhos [...]"26

Eis ontologias tradutórias, as quais contêm, no seu sistema de pensamento, uma espécie de polirritmia ontológica que sustenta ritmos e morfologias existenciais distintos, a um só tempo. Destarte, a associação entre forças cultivadas pelos bantu-kongo e santos católicos, conforme aludido

\footnotetext{
${ }^{25}$ La pensée philosophique Kongo n'est ni tribale ni raciale [...] C'est une philosophie qui venère le bon maître, même si celui-ci émergeait en dehors du cercle kongo, c'est l'application systématique de leur principe politico-philosophique de "Konso kwela mama (nkumbu andi), tata"- Quiconque épouse notre mère, c'est notre père - s'il peut affirmer, par ses qualités, quil est un "père" (chef) pour notre société Kongo.

${ }^{26}$ [...] les radiations des ondes des grands maîtres, bakulu bakula, de tous les âges et de toutes les civilisations qui atteignent son cerveau à travers les rêves [...]
} 
anteriormente, parece mostrar, complexamente, uma inscrição filosófica pluriontológica (não se trata de multiculturalismo) gravada numa cosmologia que antecede historicamente o nascimento do cristianismo. Parece haver uma combinação entre kundu inato para o devir-outro e a ciência (kindoki) que reconhece a necessidade conjuntural para tornar-se outro, permanecendo-se (dinamicamente) no que é nevrálgico.

Essa pluriontologia faz-se notável na própria capa do livro do pensador congolês Zamenga B., intitulado "Kindoki: fonte de filosofias e religióes africanas" ${ }^{27}$, a amparar a nossa análise até agora. Nela, vê-se a figuração de um ente morfologicamente composto por uma cauda de réptil; face de um símio com aparentes traços humanos e felinos; um braço como pata de onça e outro como pata de um equino, caprino ou bovino; uma perna humana e outra de ave; e o dorso coberto por pelos de algum provável mamífero. Depreende-se dessa imagem que alteridades, pelo que é efetivado por kundu ou kindoki, interagem e constituem um corpo comum (e pluriontológico). No entanto, é imperceptível o que as liga/diferencia e faz interagir.

\section{Consideraçóes Finais}

Estamos diante de um sistema específico e coletivo de pensar, a cosmologia kongo, que, a nosso juízo, não alija nem coloca na primeira ou última causa a escuridão luminosa do insondável. Ela mora na pluralidade de centros e é húmus fértil para o que brota em n'toto (terra), assim como no que a nossa experiência, reflexão e imaginário possam galgar. A ecologia que marca toda a possibilidade de viver é transversalmente (não como transcendência, mas como pertencimento ao próprio ecológico) constituída por pendores à outridade e, necessariamente, pela interação, a qual faz mesmo o vazio interagir com a ocupaçáo de vida que se apreende de modo mais direto. A ontologia, aqui, outra, no que diz respeito ao ser (substantivo ou verbal) da metafísica ocidental, preenche-se por viver, mesmo quando se espera a inescapabilidade da morte, da finitude ôntica de viver, uma vez que a memória comunitária ou individual do que vive pode re-acender a vida que viveu, agora vida-outra. Entre o que surge e a opacidade de musoni, pode-se acessar a relação. Aliás, quando se pensa em acontecimentos originários, há que se pensar em termos relacionais e copertencentes.

${ }^{27} \mathrm{O}$ título original, em francês e kikongo, da referida obra de 1996 é Kindoki: source des philosophies et des religions africaines. 
Ainda que seja comum se afirmar, entre os ba-kongo - e, nesse caso, seria possível nos estender à grande parte das civilizaçóes africanas - , que a comunidade vem antes do indivíduo, pensemos, indo mais fundo nessa conceituação fundamental, que o "antes" se dá em termos de uma relação entre coletivo e singularidade, sem que possamos instaurar uma logicidade calcada nos sequenciamentos temporais subordinativos. $\mathrm{O}$ que nos dá indícios de anterioridade (no sentido de prioridade) é a relação entre a comunidade $(k a n d a)$ que conforma a pessoa (muntu) e a pessoa que desembrulha de dentro de sua "matéria escura" interna certa comunidade; mundo a partir de fora e mundo a partir de dentro; kalunga e vazio; dinâmicas que nos mostram o complexo como plataforma básica para que se realizem as existências formadoras do mundo-natureza, o qual, justamente, pela interação entre particulares e compostos (os quais, em geral, conceitualmente, se revezam, a depender da percepção), não é, sob nenhum aspecto, abstração, mas circunstâncias.

A diáspora negra, no continente americano, além de ter sido, forçosamente, alter-ação em níveis profundos e traumáticos, sendo os seus partícipes tornados outros, conservou um fundamental princípio (nkingu) de alter-ação circunscrito por filosofias africanas, notadamente destacada, neste texto, a filosofia kongo. Sabe-se que o sistema operado por dentro (kimpa) se distingue do sistema visualizado por fora $(f u)$ e, por isso, podem-se vislumbrar dois movimentos de alter-ação (ação de alteridade) opostos: um presentifica uma entorse de dor estrutural coletiva promovida por políticas racistas de estados hegemônicos e o outro presentifica a poética cosmológica profunda que concedeu ao encantamento a infinitude que a dor não seria capaz de alcançar, ainda que seja geracionalmente duradoura.

$\mathrm{O}$ kundu e o kindoki que confluem à transmutação não foram depositados em nenhum objeto esgotável ao longo das seculares travessias entre a África subsaariana e o continente americano. Os corpos que performaram suas filosofias e cosmologias, e trouxeram suas "escritas performativas" - para dialogarmos, pontualmente, com o pensamento do teórico e dramaturgo nigeriano Irobi (2012) - ultrapassaram as corporalidades de partida, no seu contínuo movimento de outridade, e legaram novas fisicidades, inclusive aquelas que não perecem na morte ordinária. Fundamentalmente, o que a descendência negro-africana bantu-kongo, além de outras afrodescendências, mostram, por meio das frestas nas estruturas escravista e colonialista, é que a fusão entre ética e ontologia, ao seu modo, coloca "viver em relação" com ênfase ontológica em "viver" e em "estar em relação" - como o único acontecimento (plural) sobre o qual se pode, se deve e se quer pensar. 
SANTOS, T. S. N. Other resonances and ontologies: thinking with the Bantu-Kongo thinking. Trans/Form/Ação, Marília, v. 45, p. 149-168, 2022. Edição Especial.

\begin{abstract}
In light of fundamental aspects of Bantu-Kongo thinking and in line with contemporary thinkers, such as Bunseki Fu-Kiau and Zamenga B., this article aims to reflect on ontologies distinct from those of Euro-Western hegemony. Such ontologies are experienced in part of the African continent and have been moved to Afrodiasporic territories, such as Brazil, although with adaptations, through cosmological practices that situate ancestry in a central place. The ideas of "pluriontological sameness" (as we coin with a hermeneutic basis in Kongo philosophy), opacity (from Édouard Glissant's theoretical suggestion), stages of the Kongo cosmogram, emptiness, transmutation, inclination towards otherness, science of sorcery, system, ecological entities, inter-actions propose complex possibilities of being-living, in relation, which are radically far from metaphysics and ethics developed in the heart of Western thinking, as well as can dialogue with them, which makes us, by thinking on the side of the Afrodiasporic margin of the Atlantic, consider the tensions between these different ways of thinking that occupy asymmetric spaces in historical constructs.
\end{abstract}

Keywords: Filosofia bantu-kongo. Ontologia. Mesmo pluriontológico. Outridade. Entes ecológicos.

\title{
REFERÊNCIAS
}

B, Z. Kindoki: source des philosophies et des religions africaines. Kinshasa: Zabat, 1996.

BASTIDE, R. Les Amériques noires: les civilisations africaines dans le nouveau monde. Paris: Payot, 1967.

BASTIDE, R. Les religons africaines au Brésil: contribution à une sociologie des interpénétrations de civilisation. Paris: Presses Universitaires de France, 1995.

BATSÎKAMA, P. Será Mbôngi’a Ňgîndu a escola das ciências políticas no antigo Kôngo? Revista TransVersos, [S.1.], n. 15, p. 478-502, abr. 2019. ISSN 2179-7528. Disponível em: https://www.e-publicacoes.uerj.br/index.php/transversos/article/view/42055/29162. Acesso em: 21 jul. 2020. doi: https://doi.org/10.12957/transversos.2019.42055.

BOCKIE, S. Death and the invisible powers: the world of Kongo belief. Bloomington, Indianápolis: Indiana University Press, 1993.

CASTRO, E. V. Metafísicas canibais: elementos para uma antropologia pós-estrutural. São Paulo: Ubu, n-1, 2018.

COBE, F. N. Novo dicionário português kikongo. Luanda: Mayamba, 2010. 
DOUTRELOUX, A. L’ombre des fétiches: sociétés et cultures yombe. Louvain: Nauwelaerts, 1967.

DURANT, W. The story of philosophy: the lives and opinions of the world's greatest philosophers from Plato to John Dewey. New York: Washington Square Press, 1961.

FERRETTI, S. Repensando o sincretismo. 2. ed. São Paulo: EDUSP, Arché, 2013.

FU-KIAU, K. K. B. Makuku Matatu: les fondements culturels bantu chez les kongo. Manuscrito, 1978.

FU-KIAU, K. K. B. African cosmology of the bantu-kongo: principles of life and living. 2. ed. New York: Athelia Henrietta, 2001a.

FU-KIAU, K. K. B. Self-healing power and therapy: old teachings from Africa. Clifton: African Tree, 2001b.

GLISSANT, É. Pela opacidade. Tradução de Henrique de Toledo Groke e Keila Prado Costa. Revista Criação e Crítica, São Paulo, p. 53-55. Disponível em: http://www. revistas.usp.br/criacaoecritica/article/view/64102/66809>. Acesso em: 21 jul. 2020. doi: https://doi.org/10.11606/issn.1984-1124.v0i1p53-55.

HEIDEGGER, M. Ensaios e conferências. Tradução de Emmanuel Carneiro Leão et al. 8. ed. Petrópolis, Bragança Paulista: Vozes, Editora Universitária São Francisco, 1997.

IROBI, E. O que eles trouxeram consigo: Carnaval e persistência da performance estética africana na Diáspora. Projeto História: Revista do Programa de Estudos Pós-Graduados de História, [S.1.], v. 44, jan. 2013. ISSN 2176-2767. Disponível em: https://revistas. pucsp.br/revph/article/view/9857. Acesso em: 22 jul. 2020.

JONAS, H. O Princípio Responsabilidade: ensaio de uma ética para uma civilização tecnológica. Rio de Janeiro: PUC Rio, 2006.

LÉVINAS, E. Totalité et infini: essai sur l'extériorité. Paris: Le Livre de Poche, 1990.

MACGAFFEY, W. Religion and society in Central Africa: the Bakongo of Lower Zaire. Chicago: University of Chicago Press, 1986.

MELLO E SOUZA, L. Revisitando o calundu. In: GORENSTEIN, L.; CARNEIRO, M. L. Tucci (org.). Ensaios sobre a intolerância: Inquisição, Marranismo e AntiSemitismo. São Paulo: Humanitas, 2002. p. 293-317.

MORA, J. F. Diccionario de filosofía abreviado. 6. ed. Buenos Aires: Sudamericana, 1977.

MOTT, L. O calundu-Angola de Luzia Pinta: Sabará, 1739. Revista do Instituto de Arte e Cultura, Ouro Preto, n. 1, p. 73-82, dez. 1994.

NASCIMENTO, Wanderson Flor do. Aproximaçóes brasileiras às filosofias africanas: caminhos desde uma ontologia Ubuntu. Revista Prometeus Filosofia, v. 9, n. 9, p. 231-245, dez. 2016a. ISSN 2176-5960. Disponível em: <https://seer.ufs.br/index.php/ prometeus/article/view/5698. Acesso em: 21 jul. 2020. 
NASCIMENTO, W. F. do. Sobre os candomblés como modo de vida: imagens filosóficas entre Áfricas e Brasis. Revista Ensaios Filosóficos, v. XIII, p. 153-170, ago. 2016b. Disponível em: http://www.ensaiosfilosoficos.com.br/Artigos/Artigo13/11_ NASCIMENTO_Ensaios_Filosoficos_Volume_XIII.pdf. Acesso em: 22 jul. 2020.

NOGUERA, Renato. Denegrindo a filosofia: o pensamento como coreografia de conceitos afroperspectivistas. Griot: Revista de Filosofia, Amargosa, v.4, n.2, p. 1-19, dez. 2011. Disponível em: https:/www3.ufrb.edu.br/seer/index.php/griot/article/view/500. Acesso em: 22 jul. 2020.

OYEWUMI, O. Visualizing the Body: Western Theories and African Subjects. In: COETZEE, P. H.; ROUX, A. P. J. (ed.). The African Philosophy Reader. New York: Routledge, 2002. p. 391-415.

RAMOSE, M. African philosophy through Ubuntu. Harare: Mond Books, 2003.

RODRIGUES, N. O animismo fetichista dos negros baianos. Organização de Yvonne Maggie e Peter Fry. Rio de Janeiro: UFRJ/Biblioteca Nacional, 2006.

\section{SANTOS, T. S. N. A cosmologia africana dos Bantu-Kongo por Bunseki Fu-Kiau:} tradução negra, reflexóes e diálogos a partir do Brasil. 2019a. Tese (Doutorado em Estudos da Tradução) - Faculdade de Filosofia, Letras e Ciências Humanas, Universidade de São Paulo, São Paulo, 2019. doi:10.11606/T.8.2019.tde-30042019-193540.

SANTOS, T. S. N. Tradução, interações e cosmologias africanas. Cadernos de Traduçáo, Florianópolis, v. 39, p. 65-77, dez. 2019b. ISSN 2175-7968. Disponível em: https:// periodicos.ufsc.br/index.php/traducao/article/view/2175-7968.2019v39nespp65. Acesso em: 22 jul. 2020. doi:https://doi.org/10.5007/2175-7968.2019v39nespp65.

SARTRE, J. P. O ser e o nada: ensaio de ontologia fenomenológica. Tradução de Paulo Perdigão. 15. ed. Petrópolis: Vozes, 2007.

SILVEIRA, R. Do calundu ao candomblé: os rituais de fé africanos ganham seu primeiro tempo no início do século XIX. In: FIGUEIREDO, Luciano (org.). Raízes africanas. Rio de Janeiro: SABIN, 2009.

TALL, E. K. Le candomblé de Bahia: miroir baroque des mélancolies postcoloniales. Paris: CERF, 2012.

TEMPELS, P. La Philosophie Bantoue. Paris: Présence Africaine, 2013.

UNGER, N. M. O encantamento do humano: ecologia e espiritualidade. São Paulo: Loyola, 1991.

Recebido: $13 / 8 / 2020$

Aceito: $21 / 01 / 2021$ 